TITLE:

\title{
Measuring Regional Wealth and Assessing Sustainable Development: An Application to a Disaster-Torn Region in Japan
}

\section{AUTHOR(S):}

Yamaguchi, Rintaro; Sato, Masayuki; Ueta, Kazuhiro

\section{CITATION:}

Yamaguchi, Rintaro ...[et al]. Measuring Regional Wealth and Assessing Sustainable Development: An Application to a Disaster-Torn Region in Japan. Social Indicators Research 2016

\section{ISSUE DATE:}

2016

URL:

http://hdl.handle.net/2433/205681

\section{RIGHT:}

The final publication is available at Springer via http://dx.doi.org/10.1007/s11205-015-1106-3. The full-text file will be made open to the public on 24 September 2016 in accordance with publisher's 'Terms and Conditions for Self-

Archiving'.; This is not the published version. Please cite only the published version.; この論文は出版社版でありません 。引用の際には出版社版をご確認ご利用ください。 
Measuring regional wealth and assessing sustainable development:

an application to a disaster-torn region in Japan ${ }^{1}$

Rintaro Yamaguchi*, Masayuki Sato**, and Kazuhiro Ueta*

* Graduate School of Economics, Kyoto University

Yoshidahonmachi, Sakyo-ku, Kyoto 606-8501 Japan.

**Graduate School of Human Development and Environment, Kobe University

\begin{abstract}
We construct a regional comprehensive wealth as an indicator of sustainability in Miyagi Prefecture, Japan. Of particular interest is the change in wealth before and after a natural disaster, since the index could serve as a benchmark of investment into postdisaster reconstruction. We first discuss an optimum spatial unit of wealth accounting and sustainability analysis. The resultant regional wealth index had already been slightly declining during the 2000s due to stagnant investment into capital assets, oil capital loss, and budget deficit burden, until a natural disaster made the region significantly unsustainable. This wealth trend also differs from what emerges from the figures in Inclusive Wealth Report 2012. Including population decrease makes the wealth per capita look better, whose interpretation warrants caution due to the neglected forward-looking demographic change in a developed nation.
\end{abstract}

JEL Codes: E01, J1, O1

Keywords: inclusive wealth; sustainable development; genuine savings; disaster reconstruction; population change

1 The authors appreciate beneficial comments from (many) anonymous referees, Federico Castillo, Masaaki Kuboniwa, Shunsuke Managi, Anil Markandya, Alistair Munro, Ayumi Onuma, Itsuo Sakuma, Michinori Uwasu, participants of workshops/sessions at Kyoto, Senshu, SEEPS 2013 (Kobe, Japan), EAAERE 2014 (Busan, South Korea), 17th International Economic Association World Congress (Dead Sea, Jordan), and the $5^{\text {th }}$ World Congress of Environmental and Resource Economists (Istanbul, Turkey). Grant-in-Aid for Specially Promoted Research (26000001) by Japan Society for the Promotion of Science (JSPS), as well as Social Scientific Survey of Great East Japan Earthquake by JSPS, are also acknowledged. 


\section{Introduction}

Ever since the seminal discussion by World Commission on Sustainable Development in 1987 , the so-called weak sustainability discussion has spawned two parallel streams of the empirical literature, one focused on the flow metrics of sustainability, commonly called genuine savings (Pearce and Atkinson, 1993; Hamilton and Atkinson, 2006; World Bank, 2010; Aronsson and Löfgren 2010), and the other on wealth metrics (World Bank, 2006; Arrow et al., 2012; UNU-IHDP and UNEP, 2012). However, these two research spheres are theoretically interlinked in that an increase in wealth in a broad sense is critical for the development of sustainability.

These two reports, or most sustainability indicators in general for that matter, treat the nation as the spatial unit of analysis, which then must be disaggregated into local indicators to become relevant for smaller constituencies in large heterogeneous nations such as China, India, and the US. This point is especially pertinent for region-specific factors such as the extraction of natural resources or response to natural disasters. For example, most of the evaluation of the 2011 Tohoku earthquake and subsequent tsunami, including the accident at the Fukushima Daiichi Nuclear Power Plant, focused on the damage caused to conventional indicators such as regional GDP or manufactured stock. However, although these measures offer a representation of what has happened as well as suggestions for a short-term action plan, the object of measurement necessarily needs to be extended in order to assess regional sustainable development in a comprehensive sense.

Based on the foregoing, the present article measures prefectural wealth change in Japan based on a case study of Miyagi Prefecture between 2000 and 2011, following the recent contribution of Arrow et al. (2012). Our contribution to the body of knowledge on this topic lies in the following four interrelated points. First, we conduct sustainability assessment at the regional level as opposed to the country level by tapping into detailed "bottom-up" data in order to construct a regional comprehensive wealth index. Such a regional index may serve as a crucial input for social evaluators and planners at the local level. Moreover, it makes an interesting comparison with the recent publication of UNUIHDP and UNEP (2012; p.63), which concluded that Japan on the whole is placed in a favorable and rare situation, since per capita changes in inclusive wealth index and natural capital are both positive. Our results demonstrate that this does not necessarily apply to a subregion if we take a closer look. Second, we use this index in order to measure wealth change before and after the 2011 Tohoku natural disaster, thereby 
providing policy implications for the regional investment necessary for post-disaster reconstruction. Third, we stress the relevance of future prospects, especially those of demographic structure in the framework, whereas most previous studies focus on past trends in population change. Finally, we shed light on the cost side of social investment and the social cost of taxation and debt, as proposed by Aronsson et al. (2012).

The remainder of this paper is organized as follows. In the next section, we outline the underlying framework adopted in this paper. In Section 3, we define the research scope in terms of space. In Section 4, we describe the methodology, data used, and results for each category of capital assets under study; these are aggregated to arrive at (per capita) comprehensive wealth change in order to assess sustainability. In Section 5 sensitivity analysis is performed to check robustness of our results. Section 6 compares our results with what UNU-IHDP and UNEP says about Japan. Section 7 is devoted to policy discussion on forward-looking investment in capital assets as well as on the consequences of demographic change on sustainability. Section 8 concludes.

\section{Underlying theory}

Even though our unit of spatial analysis is the prefecture level, we still draw on the well-known theory proposed by Arrow et al. (2012) and UNU-IHDP and UNEP (2012). We wish to leave the basics consistent with theirs, especially for the sake of comparison we make in Section 6. Our social well-being for the time period $s \in[t, \infty)$ is defined by

$$
\mathrm{V}(\mathrm{t})=\int_{t}^{\infty} u(c(s)) e^{-\delta(s-t)} d s,
$$

where $c(\cdot)$ stands for current consumption.

It is worth noting here that consumption includes that of marketed goods as well as of quality time, leisure time, ecosystem services, and any other amenities that serve as a source of future well-being in a broad sense. Assuming that future consumption is provided by future capital stocks, which are in turn determined by present capital stocks in an iterative fashion, we can describe the value function as $V(K(t), t)$, with $K(t)$ being a score of capital assets at time t. The dynamic maximization of (1) given forecasted future streams of consumption and capitals, if well defined, provides us with an optimal consumption path. This optimality is a different concept from sustainable development, the latter of which is defined by a change in wealth:

$$
\frac{\mathrm{dV}}{\mathrm{dt}}=\frac{\partial V}{\partial t}+\frac{\partial V}{\partial K} \frac{d K}{d t}+\frac{\partial V}{\partial H} \frac{d H}{d t}+\frac{\partial V}{\partial N} \frac{d N}{d t} \geq 0
$$

where the capital vector $\mathrm{K}(\mathrm{t})=(\mathrm{K}(\mathrm{t}), \mathrm{H}(\mathrm{t}), \mathrm{N}(\mathrm{t}))$ is composed of produced capital, human capital, and natural capital, respectively. $\frac{\partial V}{\partial \boldsymbol{K}}$ can be named the shadow prices of capital 
assets.

Along the optimal path, these shadow prices would be determined by the necessary conditions for optimality, as shown by, e.g., Hamilton and Atkinson (2006), but they can also be defined in imperfect economies given the forecast of the economy from the present time to the future (Dasgupta and Mäler 2000). Equation (2) states that for development to be sustainable the proposed metrics should be calculated as the change in each capital stock multiplied by its marginal shadow price plus a non-autonomous term, as shown by the pioneering application studies of Arrow et al. (2004, 2012), UNU-IHDP and UNEP (2012), and Ollivier and Giraud (2010).

When the LHS of (2) is expressed in monetary terms, it is often called genuine savings (Hamilton and Clemens, 1999; World Bank, 2006, 2010, 2011). The non-autonomous term that appears first on the RHS of (2) specifically contains oil capital loss and total factor productivity (TFP) growth. Another complication that arises from population as a capital asset is introduced in Section 7.

3. Optimum spatial unit of wealth accounting and sustainability analysis

To the best of our knowledge, all the publications on wealth accounting, including World Bank (2010) and UNU-IHDP and UNEP (2012), measure the inclusive wealth of nations, with a few exceptions. Mumford (2012), contained in UNU-IHDP and UNEP, investigates the inclusive wealth of U.S. states and finds that the interstate inequality in wealth is not large. By contrast, Dovern et al. (2014) look into the wealth of German cities to find regional differences and strong association with housing rents ${ }^{2}$. Indeed, in principle the same methodology can be applied to any spatial unit. That spatial unit could be the whole world economy, or, in the opposite extreme, be disaggregated to the individual or household level, a conventional unit of microeconomic analysis. Thus, a relevant question to be examined here is

(a) At which spatial level is it best to conduct wealth accounting and sustainability analysis?

Relatedly, we have the following question:

(b) Which spatial level of area should achieve non-declining wealth and sustainability on its own? Specifically, is there an argument for weak substitutability among regions?

2 Romano and Ercolano (2013) study environmental virtuosity of Italian municipalities. 
These are closely interrelated questions, and answers clearly depend on the scope of "society" in the social welfare function. Below we discuss some (overlapping) aspects critical to answering these questions, thereby determining the spatial scope of social wealth, well-being, and sustainability.

Exogenous factors. The more we disaggregate spatial unit of analysis, the more exogenous factors there arise under free trade, as smaller geographical units tend to have less assets to live on. Exogenous factors, expressed in the $\partial V / \partial t$ term in (1), are not a problem in wealth accounting per se, as long as they are properly accounted for. Nor can it be argued straightforwardly that sustainability under large exogenous factors, for example, loads of imports of natural resources, is unjustifiable ${ }^{3}$. However, exogenous factors tend to be mismeasured exactly because they are exogenous and therefore uncertain and volatile. Therefore, a wealth accounting at a lower level that corresponds to, say, more than half of the economy being dependent upon (net) exports could provide a misleading piece of information.

Mobility and substitutability of capital assets. If capital assets are relatively mobile and substitutable within the same category, then national figures of wealth may suffice. That is not usually the case for a large economy: the amenity provided by Grand Canyon cannot be substituted by that of Central Park in New York, and an IT engineer in Bangalore is qualified in a different way than a civil engineer in New Delhi. Wealth measurement can be disaggregated as long as capital assets are mobile from human points of view and relatively substitutable.

Distribution of capital assets. If the area under study is a homogenous economy and thus the existing wealth accounting figures already reflect the status of a representative subregion, then accounting does not necessarily have to be disaggregated further. Suppose, in contrast, that a region can be divided into a growing industrial city and a dwindling tropical forest. Then a seemingly stable inclusive wealth trend for the whole region may gloss over a regionally heterogeneous distribution of different capital assets. Thus, heterogeneous distribution of capital assets within a region may justify a disaggregated sustainability analysis.

\footnotetext{
3 Measuring virtual sustainability by including resource consumption embodied in traded goods is one such treatment. For a discussion on its justification, see, e.g., Hamilton and Atkinson (2002) and chapter 5 of UNU-IHDP and UNEP (2012).
} 
Divisibility in technology. Nation-based macroeconomic indicators take nationwide factors of production for granted. Conventional capital is considered as if they were indivisible and subject to declining marginal productivity in total. This is not necessarily applied to other capitals in the context of inclusive wealth accounting and sustainability assessment. For example, it may seem likely that human capital (population with adequate education and health) can be divided at any level upper than an individual. However, this is not self-evident, since educated individuals can work together to yield outputs that cannot be achieved if tackled individually. Also, human capital is closely linked with social capital, the latter of which is influenced by the size of the network. Similarly, it is known that primary health status yields externality so that it works as a public good. There is also evidence that obesity may be contagious through social networks ${ }^{4}$ and that malnutrition prevails in the unit of villages and communities. Moreover, much of the debate on natural capital accounting and adjustment by ecosystem services is conducted at a level of communities and regions. Ecological production function of ecosystem into services mainly look at the local scale, and more work is needed to integrate the individual services at regional and global scale (Daily et al. 2009) as a suitable tool, but clearly it is not for a national level of accounting, except the case of climate change and others. It is increasingly common in the ecological analysis to look at landscape as a unit of analysis (Barbier 2009). As a way to focus on provision and needs of ecosystem services, Tallis et al. (2012) propose that analysis be done at a serviceshed. All things considered, it is advisable that wealth accounting be performed larger than communities.

Policy and institution autonomy. Even if it is argued that sustainability analysis should be performed at a certain local level, prescriptions cannot be put into action in the absence of a policy or institutional autonomy at that level ${ }^{5}$. One example is sustainability at the global level, which is hard to improve without an institution like the world

\footnotetext{
${ }^{4}$ See Cohen-Cole and Fletcher (2008) and the references therein for details.

${ }^{5}$ It would be unrealistic for a small town or community to be totally independent in terms of its economy or ecology. For example, it has been sometimes argued that each region should be self-sufficient in terms of its energy consumption. However, this would be overly inefficient if, say, a city enjoying the benefit of agglomeration had to generate electricity for its own municipality using an expensive plot of urban land or a countryside rich in ecosystem had to destroy natural habitat to manufacture consumption goods to provide for its own citizens.
} 
government.

Data availability. In practice, this constraint bites the most. In Japan, for example, SNA is well practiced at the prefectural level, but not any further.

Although the above argument is neither formal nor mutually exclusive, there are some implications. In light of them, wealth accounting at a prefectural level may prove to be useful input, and we define the prefecture as the spatial unit of analysis herein, because of limited mobility and substitutability, heterogeneous distribution of capital assets, more or less decentralized local government, and data availability at levels further down than prefectures. Of course, disaggregated wealth figures do not substitute national figures, but they complement each other by comparison.

The Tohoku region along the Pacific coast is made up of Aomori, Iwate, Miyagi, and Fukushima Prefectures. All the four prefectures were damaged to varying degrees during the 2011 disaster. Of the four, we chose Miyagi Prefecture because it is the largest in terms of population (2.3 million), economy (8,007 million yen in 2009), and loss of human lives (11,729 as of January 2013). Data availability constrained our analysis to analyzing change in wealth from 2000 to 2005, 2010, and 2011.

\section{[Place Figure 1 here]}

\section{Wealth measurement}

In this section, we briefly explain the methodologies used to account for each capital asset for the years 2000, 2005, and 2010 and present the data and results. We focus on manufactured capital, human capital, and natural capital as typical capital assets. The damage to each category in the aftermath of the 2011 disaster was estimated in varying ways, while the 2000 market exchange rate of 107.77 Japanese yen $=1$ US dollar was applied throughout 6 . All the relevant parameters and assumptions are summarized in Appendix.

\footnotetext{
${ }^{6}$ While the market exchange rate is appropriate for manufactured capital and other tradable resources, it might overvalue capital assets generated from non-tradable goods and services. The situation is reversed if we study relatively poor countries. In this regard, an alternative would be to use the PPP rate.
} 


\subsection{Produced capital}

Measuring manufactured capital involves compiling stock estimates in one of two ways: (i) by accumulating investment and depreciation in a permanent way or (ii) by accumulating them in addition to the known capital stock in the reference year. We follow the latter approach, namely,

$$
\mathrm{K}(\mathrm{t})=\mathrm{K}(\mathrm{s})+\sum_{\tau=s}^{t}(I(\tau)-D(\tau)+o(\tau)),
$$

where $I(\tau), D(\tau)$, and $o(\tau)$ stand for gross investment, depreciation, and other changes in volume at time $\tau$, respectively. This formulation differs from previous inclusive wealth accounting only in including the $o(\tau)$ term. It is customary in the System of National Accounts that destruction of fixed assets due to exceptional events is not recorded in flow accounts and only appears in other changes in volume of assets account.

Manufactured capital is generally divided into housing stock, corporate stock such as plants and machinery, and public stock. We simply combine these stock categories in $\mathrm{K}(\mathrm{t})$. Our base year, s, is set to be 1975 because of the availability of prefectural data from this point. Considering that the lifetime of physical capital in Japan is somewhat shorter than the world average, the use of this base year is sufficient.

According to our data derived from the Cabinet Office of Japan, corporate investment peaked in 1991 at approximately $\$ 15,000$ million, just before the expansion of the automobile industry in the northeast region started. Since then, 50-60\% of gross investment has flowed from the corporate sector and 20-30\% from public investment. Housing investment has been declining since the adult population in the prefecture peaked in 2000 at approximately two million. Ordinary calculations according to (3) yield the capital stock levels shown in Table 1.

\section{[Place Table 1 here]}

To assess the change in physical capital after the 2011 disaster we use the capital stock- damage ratio, which is estimated to be $11.9 \%$ of private and public physical stocks in Miyagi Prefecture (Development Bank of Japan 2011)7. This study divides total predisaster stock into corporate, housing, public, and other assets as well as into coastal and

\footnotetext{
7 We use the damage rate estimated by the Development Bank of Japan, but its estimated capital stock in monetary terms per se cannot be employed here, because this figure is what it would cost if the assets were purchased in the market from scratch. Obviously, this does not reflect the depreciation that has eroded the assets over time (Harada 2012).
} 
inland areas. Also, it could be the case that the destroyed capital assets had already been depreciated economically anyway, so depreciation is not accounted for in the year 2011 only to avoid double accounting. It is worthwhile noting that most damage to physical and human capital occurred in coastal areas, which were engulfed by the largest tsunamis in modern history.

\subsection{Human capital}

Although Hamilton and Clemens (1999) used educational expenditure to proxy for human capital, the pioneering work of Mincer (1974) inspires human capital computations in the recent wealth accounting literature, since it better reflects outputbased investment rather than just an expenditure input. The recent analysis of Ferreira and Hamilton (2010) and Arrow et al. (2012) also covers health within human capital; however, the methodology of calculating health capital is far from established, leading to its seemingly high profile among capital assets in previous work (UNU-IHDP and UNEP 2012). In addition, we suspect that this approach of accounting for health still risks double counting educational investment. Therefore, we follow Arrow et al. (2012) but focus on education in inferring human capital stock. The mass of human capital stock is simply expressed as

$$
\mathrm{H}(\mathrm{t})=\mathrm{P}(\mathrm{t}) \mathrm{e}^{\mathrm{rT}},
$$

where $\mathrm{P}(\mathrm{t})$ denotes the population of persons aged 15 years old and older at $\mathrm{t}^{8}, \mathrm{r}$ the rate of return on education, which is set at $8.5 \%$, and $\mathrm{T}$ educational attainment. A national update on the educational attainment of this population can be retrieved from Barro and Lee (2011). The shadow price of one unit of human capital is more complex:

$$
p_{H}(\mathrm{t})=\int_{t}^{t+m} \frac{W(\tau)}{\mathrm{L}(\tau) \mathrm{e}^{\mathrm{rT}}} \mathrm{e}^{-\delta \tau} d \tau
$$

where $\mathrm{W}(\mathrm{t})$ is the total wage bill, $\mathrm{L}(\mathrm{t})$ is the employed proportion of the adult population from the Labor Force Survey, $\delta$ is the social discount rate, and $m$ represents the average remaining working years for the cohort of people in question. The total wage bill $\mathrm{W}(\mathrm{t})$ is taken from prefectural employee wages, the social discount rate is assumed to be $5 \%$ per annum, and the parameter $\mathrm{m}$ is preliminarily set to be 20 years.

[Place Table 2 here]

\footnotetext{
8 Through this assumption, we also include unemployed and discouraged workers in human capital, because this reflects the potential assets.
} 
Table 2 shows human capital and its values for 2000, 2005, 2010, and 20119. The table highlights that capital increased from 2000 to 2010 owing to the nationwide improvement in educational attainment (from 10.923 to 11.582 ) combined with the rising number of adults (from 2,010k to 2,038k). The total wage bill decreased from 4,752 to 4,146 billion yen during the decade, but here the decade average is employed here. Educational attainment is assumed to be unchanged from 2010 to 2011 (11.582 years). Consequently, the human capital stock decreased from the previous year owing to the disaster death toll as well as a net outflow to other regions.

\subsection{Natural capital}

Much of the original motivation for "green" accounting came from the depletion of oil reserves and the effect of such resource scarcity on economic growth. The resource economics literature (e.g., Hartwick, 1977; Dasgupta and Heal, 1979; Dixit et al., 1980) has been especially concerned with exhaustible resources, particularly in resource-rich nations (e.g., Vincent et al., 1997; Hamilton and Bolt, 2004; van der Ploeg, 2010). However, because Japan produces virtually no exhaustible resources, we confine our analysis to renewable resources (fish, forest, and agricultural land) in addition to contribution to carbon stock.

\subsubsection{Fishery resources}

The fishing industry is an integral sector in coastal areas, and thus it is reasonable to include its capital assets in our sustainability assessment. After the 2011 disaster, it took some time for this sector to recover its human capital (fishers) and manufactured capital (fishing vessels, port facilities, and cold chains such as refrigerators) in order to resume fishing activities. It is worth noting that the fishing stock itself has no direct use value without the means, so that what we account for is a potential fishing stock under the assumption that we have access to $i^{10}$. Another caveat is that the fishery resource is the

\footnotetext{
9 As with physical capital, the figures for human capital are counted for the Japanese fiscal year (from April to March). The damage after the earthquake on March 11, therefore, is supposed to be contained under the FY 2010 technically, but the labor force figures are the fiscal year average, and thus we assume that the majority of the damage was not reflected in the 2010 data.

10 This observation gives rise to two potential arguments. First, fishery production is a joint output of fishery resource, capital and labor, so that its accounting price depends upon the scarcity of the latter two production factors. The argument here is reminiscent of ecosystem services as a joint product of produced and natural capital (Boyd and Banzhaf 2007). Second, wealth accounting from the capability approach (Sen
} 
most migrant kind in wealth; so that it is not always well-defined where they belong to. Thus it may appear to be a strong assumption to count them as the prefecture's asset, but it can be rationalized by assuming the other conditions being constant (preferences, technology, behavior of others), and more importantly, by the fact that it is the potential assets that are reckoned in wealth accounting.

We recall that the standard Schaefer harvest function takes the form

$$
H=q E S,
$$

where $\mathrm{q}$ is a coefficient of catchability (assumed to be $0.1 \%$ ), $\mathrm{E}$ is the number of fishing vessels, and $\mathrm{S}$ is the fish stock (for tuna, bonito, and other long line fishery).

We use the market price of tuna (frozen fish, weighted average) to determine the shadow value of fishing stock. As a consequence, the fish stock estimate for 2011 is almost quadruple that of the previous year, because many vessels were abandoned in the aftermath of the disaster (Table 3). While the above argument is an indirect measurement of the fish stock, this recovering trend is consistent with ecological research. Fukushima Prefecture (2013) finds that, on the average of the all studied fish species, the catch per unit effort $(=H / E)$ reached three times larger after the earthquake.

[Place Table 3 here]

\subsubsection{Forest}

Forest covers almost three fourths of the total land area in Japan and therefore considered to be another non-negligible class of typical renewable resources. Indeed, UNU-IHDP and UNEP (2012) reckons that 75\% of natural capital change in the nation is explained by forest resources. In the following, we confirm that Miyagi Prefecture is no exception. In the prefecture under study, there are around 20 thousand entities engaged in forestry, and logging is an active industry, although its share of GDP is limited. Moreover, after the 2011 earthquake, the importance of forests as a defense against wind, tsunami, and natural disaster was highlighted.

Data for forest cover are retrieved on a prefectural basis, but otherwise we followed the previous studies of World Bank (2006) and UNU-IHDP and UNEP (2012) in

1982) should reflect the status of other capitals (produced and human capital in the current example) associated with the capital in question, which in turn determines accounting prices. Although this is a critical issue, particularly regarding human capital (unemployment), in our current paper, we opt to account for potential stocks of a capital, regardless of its interaction with other capital assets, in order to be consistent with other studies and because of data availability. 
considering that the value of forests is made up of timber and other benefits. The unit value of timber is substituted by that of industrial roundwood removals in FAO (2010) only, because the volume of woodfuel removals is negligible and its unit value is not available ${ }^{11}$. They are available only for the years 1990,2000 , and 2005 , and the other years are linearly interpolated. Rental rates, i.e., the share of rents in the market price, is assumed to be constant at 50\%, following Bolt et al. (2002).

The value of non-timber forest benefits is considered as $\$ 190$ per hectare of total forest area, which is inclusive of the accessibility assumption (Lampietti and Dixon 1995; UNUIHDP and UNEP 2012). The present value of this non-timber forest benefit is calculated assuming the discount rate of $5 \%$ and infinite horizon.

Table 4 shows that the forest stock in the past decade has been stabilizing on the order of 60 to 70 billion dollars. The earthquake did cause forestland collapse and other forestry facilities, but on the macro level had relatively minor impact on the mass of forest stock in Miyagi.

[Place Table 4 here]

\subsubsection{Agricultural land}

Agricultural land is thought to be a class of natural capital with its renewable characteristics. The tsunami caused by the Great Earthquake devastated coastal areas which include many agricultural fields that produce rice and other vegetables among other crop products. In Miyagi Prefecture, as much as 14,558 hectares of agricultural land out of 25,712 hectares in the devastated municipalities (or out of 126,188 hectares for the entire prefecture) were damaged, according to the Ministry of Agriculture, Forestry and Fisheries (MAFF). In many cases, agricultural fields were damaged in a way that surface soil was wiped out or flooded by tsunami. Damages were also caused, though less often, by cracks, liquefaction, collapse, or sediment inflow.

It is convenient to categorize agricultural land into rice (paddy) fields and other cultivated fields in the Japanese statistics. The latter category includes vegetables, fruits, livestock animals among others. The shadow price of agricultural land stock per hectare is the present value of the agricultural rent the unit land yields from now to the infinite future. The annual rent per hectare is calculated by dividing total output by arable land,

11 FAO (2010) reports that $17,803 \mathrm{~km}^{3}$ of industrial roundwood as opposed to $160 \mathrm{~km}^{3}$ of woodfuels were removed in 2005. 
separately for rice and others. The share of rents in the market prices of agricultural product is assumed to be constant at $80 \%$. For more detailed sources, see the Appendix.

By computation we estimate the net present value of paddy and other fields are 3,314 and 47,113 thousand dollars per hectare, respectively, assuming 5\% discount rate. Multiplying these figures by the physical amounts of agricultural land stock yields Table 5. This shows vividly that land stock worth as much as billions of dollars was lost in 2011.

[Place Table 5 here]

\subsubsection{Carbon stock}

Although there are natural as well as anthropogenic causes of global warming, we account for the human contribution to carbon stock as a negative investment in environmental capital stock, in line with previous studies. The approaches of previous works can be categorized into two lines. The first camp focuses on the nation's emissions of greenhouse gases regardless of any future carbon damage the nation might suffer (Hamilton and Clemens, 1999; World Bank, 2006, 2010, 2011). The other camp stresses that the real capital asset change occurs because of the damage suffered by the nation, regardless of its own emission (Arrow et al., 2004, 2012; Ollivier and Giraud, 2010).

We follow the former emissions-based approach because of the difficulty in spatially disaggregating national damage. In addition, the latter damage-based approach takes global disinvestment as given, and it would be too early to give up all mitigation opportunities. Hamilton (2012) defends the emissions-based approach on the grounds that it assumes an ultimately perfect world where damage is completely compensated responsibly by contributing nations by way of ideal instruments such as tradable permits or taxes. This is for sure an unrealistic description of the current state of affairs, but it works well as a benchmark to show the true cost of emissions.

The regional estimates (and projections for 2011) of carbon emissions at the prefectural level were taken from Kainou (2013). His calculation suggests that the emissions from Miyagi Prefecture peaked in the period 2005-2007 and then declined marginally ${ }^{12}$. By employing the results presented by Tol (2009), we obtain the latest annual shadow value of carbon emissions to be $\$ 215$ million (Table 6).

12 Murota (2008) also calculates prefectural emissions as 5,857, 5,860, and 5,876 ktC, for 2000, 2006, and 2010 (projected), respectively. While his estimates are higher than those of Kainou by the order of $1 \mathrm{mtC}$, we take the latter figures because they are exhaustive and frequently updated. 


\section{[Place Table 6 here]}

Despite the fact that corporate activities ground to a halt in the prefecture after the disaster as well as the electricity saving effort by citizens, emissions increased from the previous year in 2011, partly because carbon emissions per $\mathrm{kWh}$ increased after nuclear power plants stopped functioning.

To validate this emissions-based approach we also studied damage as an approximation of regional GDP, following Nordhaus and Boyer's (2000) region-specific findings. They claim that a 2.5 -degree temperature warming might result in damage equivalent to $0.5 \%$ of national GDP. Applying this value to regional GDP in the investigated prefecture suggests a cost of approximately $\$ 400$ million. Hence, we may safely conclude that the social cost is of the order of several hundred million dollars.

\subsection{Oil and gas capital loss}

Asheim (1986), Sefton and Weale (1996), Vincent et al. (1997), Hamilton and Bolt (2004), and Dasgupta (2009), among others, point out that capital gains from exhaustible resources should be attributed to real wealth. Since little oil or gas is produced in Japan, let alone in Miyagi Prefecture, we must calculate oil and gas capital loss on the basis of imports (Arrow et al., 2012), as long as the price rises during the period of study. More specifically, for each oil or gas exporter, capital gains in the period $[t, \Delta t]$ can be expressed as:

$$
\int_{t}^{t+\Delta t} \dot{p}_{R}(s) S(s) e^{-\delta(s-t)} d s,
$$

where $\mathrm{p}_{R}(\mathrm{t})$ denotes the resource price at $\mathrm{t}$ and $\mathrm{S}(\mathrm{t})$ is total resource reserves at $\mathrm{t}$.

This value should be added to the exporter's current contribution to real wealth. By calculating the total capital gains of exporters around the world and multiplying this figure by the prefecture's consumption share of the world total, we obtain the region's capital loss, which should be deducted from its real wealth.

In practice, we let the resource price in 2000 ( $\$ 28.50$ per barrel) rise $5 \%$ annually ${ }^{13}$. The main results are summarized in Table 6. Most notably, the oil and gas burned in the prefecture in 2011 was record high, as nuclear power plants across the nation stopped after the accident. Consequently, the region's share of oil and gas consumption is as high

${ }_{13}$ In fact, the crude oil price shot up at 13.2\% per annum during the period under study, so our assumption of capital loss is on the conservative side. 
as $0.084 \%$ of world total. Along with the rising global capital gains, the regional capital loss shot up in 2011 to around $\$ 5.7$ billion.

\section{[Place Table 7 here]}

\subsection{Marginal excess burden of taxes and debts}

There is rising concern about the public debt-to-GDP ratio in developed countries including Japan, where the rate of return on investment for physical capital is lowering while social security costs are surging (e.g., Hoshi and Ito, 2012). How are the public debts to be accounted for in the comprehensive wealth accounting? In the optimal world, projects are selected according to cost-benefit rules, meaning that the national debt outstanding is supposed to be more than cancelled out by the social profits generated by public capital assets, as far as debts are issued for the purpose of current expenses. When these debts are repaid in the future, the government collects taxes, liquidates assets, or taps into the cash flow from the employment of these assets. The current national debt outstanding is cancelled out by the current holders from a national perspective ${ }^{14}$. Hence, regarding welfare gains or losses, we are left with the question of how to tax them. In this sense, Aronsson et al. (2012) is the first to accommodate future welfare losses in genuine savings when debts are repaid. We operationalize their idea by accounting for the marginal excess burden of the net increase in public debts. This value is proxied by general government budget deficits multiplied by the GDP share of the prefecture. The results are presented in Table 8.

\section{[Place Table 8 here]}

\subsection{Adjusting for TFP growth and population change}

In line with the growth accounting literature, technological change in a broad sense should be added to the nation's real wealth, as it is a source of future wealth. Theoretically, this is shown in the $\partial \mathrm{V} / \partial \mathrm{t}$ term in equation (2). Even though prefecturallevel TFP growth data are sparse, a few studies have found the growth rate to be in the range from $1.12 \%$ (Ministry of Internal Affairs and Communications, 2008) to $2.22 \%$ (Mitsuhashi, 2010) for the period 2000-2005. These figures are still patchy, so we do not

14 Even if we account for debts as negative capital assets, the majority are cancelled out domestically, since $92 \%$ of them were held by the Japanese public at the end of 2011 (Bank of Japan, Flow of Funds Accounts). 
include the term in the adjustment of the bottom line figure of wealth per capita.

Population change also falls into the $\partial \mathrm{V} / \partial \mathrm{t}$ term in equation (2). Previous studies have adjusted for population change to arrive at a better index of social well-being, especially concerned about population growth in developing regions (Arrow et al., 2004; World Bank, 2006; UNU-IHDP, 2012). We follow the literature in order to calculate the intuitive metrics of change in comprehensive wealth per capita. Specifically, using the prefectural population data on October $1^{\text {st }}$ each year, we deduct the rate of population increase from comprehensive wealth growth. Results are described in the next section; we note that after peaking at approximately 2,372k in 2003, the Miyagi Prefectural population had already been declining.

\subsection{The bottom line}

In the next step, we consolidate the specific proportions of capital asset dynamics into comprehensive wealth indices in order to assess regional sustainability. Figure 2 displays the three pillars of capital assets expressed as stock values for 2010 and 2011. Natural capital is further broken down into agricultural land, fishery, and forest resources. As is the case for developed nations, human capital embodied in the adult population accounts for more than 70 percent of comprehensive wealth, which does not change dramatically before and after the natural disaster. Of course, this is not to say that the human loss has been negligible, since the index merely comprises the knowledge and skills embodied in the general public and neglects all the other value of life as such. Produced capital comes in the second position, accounting for approximately one fifth. Within the natural capital, forest (most of which are untapped) and land comprises the lion's share.

\section{[Place Figure 2 here]}

However, the stock value of wealth per se does not provide ample implications for policymakers. What matters in sustainability analysis is a change in wealth, as shown in annualized terms in Table 9. This table shows that the erosion of manufactured capital following the 2011 disaster was massive, but that it had been gradually decreasing even before this event in any case. Further, human capital incurred severe damage in the disaster, but, again, increase in this specific capital in the latter 2000s was also stagnant.

Overall, there is a trend of comprehensive wealth slowly turning negative in the late 2000s. Unfortunately, this subtly unsustainable trend was driven down further to an 
unsustainability level in the aftermath of the 2011 disaster. In the meanwhile, oil capital loss and the marginal excess burden of budget deficits have been steadily increasing.

\section{[Place Table 9 here]}

The annualized wealth change rate presented in Table 10 includes the effects of population change. Carbon damage, oil capital loss, and the marginal excess burden are expressed in terms of the last period's manufactured capital. Based on our calculation of comprehensive wealth change per capita, again the latter 2000's already witnessed slightly unsustainable path. The population decrease for all periods seems to imply that fewer resources are needed to meet consumption needs. Therefore, we conclude this section by noting that regional development during the study period can be assessed as slightly (un)sustainable, with the exception of 2011.

\section{[Place Table 10 here]}

\section{Sensitivity analysis}

In this section, we see how robust the results in the previous section are. Table 11 summarizes the sensitivity analysis of the change in comprehensive wealth per capita.

To begin with, the base case discount rate (5\%) was applied to calculation of the present value of forest benefits, agricultural land, and the value of remaining years of human capital. Varying this rate between lower (2\%) and higher (8\%) slightly changes the assessment from negative growth to positive growth, specifically for 2005-2010. Lower discounting does not necessarily work to improve the change in wealth per capita, as is expressed in the first half of the 2000's. As expected, longer working years remaining contributes to raising the wealth per capita change figure by pushing up the value of current human capital. In terms of policy implication, this corresponds to younger labor participation or, as discussed later, a raise in the retirement age.

A higher (lower) catchability coefficient translates into a lower (higher) estimate of fishery stock, and this particularly affects the final single year period, as the fishing loading figure for 2011 is unusually low. Various levels of social cost of carbon (15, 50, and 500 dollars per tC) also affect the change in comprehensive wealth, as described in Panel (D), but the order of the magnitude of sensitivity is not significantly high.

In the base case, oil price is assumed to increase 5\% every year during the study period, which is lower than the actual increase, and this is varied between $-5 \%$ and $20 \%$ in our 
sensitivity analysis. Notably, an annual increase of $20 \%$ certainly makes the indicators much worse. While it is not plausible to assume this level of oil price increase, it can happen for a short time, as the international oil market experienced in 2008. In contrast, sensitivity in the marginal excess burden of 0.1 or 0.5 is not notable.

In sum, panels (A)-(E) demonstrate that our results are fairly robust. The most sensitive parameter turns out to be the discount rate, as is applied to the shadow prices of several capitals. However, this does not change the overall assessment of the trend in wealth, altering the change rate at the order of the magnitude of $0.1 \%$.

\section{Comparison with Inclusive Wealth Report 2012}

Aside from the trend of inclusive wealth figure, it is worth comparing our results with existing benchmarks. The second edition of UNU-IHDP and UNEP (2012) reports that manufactured and human capital account for almost one and three thirds of comprehensive wealth in Japan, respectively. In their first edition (2012), this is the only country out of the twenty samples where natural capital has increased during the period of 1990-2008, partly because forest resources slightly increased and, more implicitly, that its economy largely rests on resource imports.

While our results are consistent with the overall breakdown of capital stocks (Figure 2 ), there are some important differences if we focus on the change in assets. The lower panel of Figure 3 shows implied change of wealth in the periods 2000-2005 and 20052010, constructed from UNU-IHDP and UNEP (2012) and adjusted by the population of our study region, which is approximately $1.9 \%$ of the nationwide figure. The upper and lower panels make a stark contrast. First, the order of the magnitude of the change in some capital categories is significantly larger, and the changes become more volatile, as we disaggregate spatial unit. This is not surprising, considering that national aggregation works as "spatial smoothing". Second, some factors not assessed in UNUIHDP and UNEP (2012) may be non-negligible. In particular, marginal excess burden from public debts and perhaps volatile fishery resources may be contributing much to the change in overall wealth. Third, while no data after 2011 for the whole nation is available, regional disaggregates naturally highlight the consequences of the disaster in wealth figures. Physical, human, and natural capitals all stand out in this respect. Our example of the prefecture clarifies that regional disaggregates may show very different pictures of changing wealth.

[Place Figure 3 here] 
7. Discussion and further thoughts on population

To recap, regional development had barely been sustainable until the earthquake hit the region, if we look at the comprehensive wealth on a per capita basis. Although this assessment suggests that past development has been sufficient to guarantee the sources of future well-being, it ignores future investment strategy, which is a normative issue that no previous studies have addressed adequately. Ideally, alternative policies should be evaluated using the same set of shadow prices adopted herein (see Dasgupta and Mäler 2000), but this evaluation is outside the scope of the present paper. Rather, we focus on three prescriptive points relevant to disaster reconstruction and forwardlooking investment strategies.

First, while acknowledging that inclusive wealth accounting is not meant for prescription, it is tempting to ask how much investment should be made for reconstruction and sustainability and where it should be deployed. The Miyagi Prefectural government announced that $\$ 120$ billion (JP¥12,830 billion) is needed for the reconstruction of the prefecture. The wealth decline presented in Table 9 suggests that comprehensive wealth was damaged on the order of magnitude of $\$ 24$ billion $^{15}$. While these figures substantially differ and may rovoke discussion on the benchmark to which capital assets should be reconstructed, what matters more is not the figures themselves but the types of capital to be invested. If the marginal rate of return on investment in each capital asset were equal, as in an optimal economy, investment into any capital asset would be indifferent. Under such conditions, Table 9 also implies that, as well as investing in physical capital reconstruction, resources should be saved for the creation of human capital.

Second, oil capital loss is expected to continue eroding the capital base, as the nation continues to rely on outside natural resources. Insofar as this assumption rings true, investment in renewable energy is a sensible idea to nullify this degree of capital loss and make up for the depreciation of other assets such as through carbon damage ${ }^{16}$. Investing in renewable energy is made by augmenting natural capital, the investment generates double dividend.

15 This amount includes not only the direct consequences of the disaster but also unrelated capital depreciation, such as the decrease in human capital, carbon emissions, excess burden, and oil capital loss.

16 Of course, if future resource price prospects decline owing to nonconventional sources, this benefit lessens. 
Third, and most importantly, future population growth is crucial when considering comprehensive investment per capita into a society facing demographic change. Given that the regional population is expected to decrease, it is questionable whether it is sufficient to invest to the extent that comprehensive investment in the whole region is greater than the rate of population decline. This investment is further complicated because the demographic structure is also bound to change ${ }^{17}$.

To demonstrate this point it helps to fine-tune the model of Arrow et al. (2003). Let K, $\mathrm{L}$, and $\mathrm{N}$ denote physical capital, the labor force, and the retired population, respectively. Then, we can apply dynamic optimization to show that, along an optimal path, the increase in comprehensive wealth per capita in monetary terms can be expressed by 18

$$
\frac{\dot{W}}{N+L}=\dot{k}+\left(k+\frac{p_{N}}{p_{K}}\right) \frac{N}{N+L} g_{N}+\left(k+\frac{p_{L}}{p_{K}}\right) \frac{L}{N+L} g_{L},
$$

where $\mathrm{k}=\mathrm{K} /(\mathrm{N}+\mathrm{L})$ is per capita physical stock, and $\mathrm{p}_{\mathrm{N}}$ and $\mathrm{p}_{\mathrm{L}}$ stand for the shadow prices of the labor force and retired population, while $g_{N}$ and $g_{L}$ stand for the growth rates of the working and retired populations and

$$
\begin{aligned}
& k+\frac{p_{N}}{p_{K}}=\int_{t}^{\infty}\left[\frac{u}{u \prime}-\frac{L}{N+L}\left\{\left(g_{N}-g_{L}\right) k+F_{L}\right\}\right] e^{-\int_{t}^{S}\left\{F_{K}(K(\tau), L(\tau))-g_{N}\right\} d \tau} d s, \\
& k+\frac{p_{L}}{p_{K}}=\int_{t}^{\infty}\left[\frac{u}{u \prime}+\frac{N}{N+L}\left\{\left(g_{N}-g_{L}\right) k+F_{L}\right\}\right] e^{-\int_{t}^{S}\left\{F_{K}(K(\tau), L(\tau))-g_{L}\right\} d \tau} d s,
\end{aligned}
$$

where $\mathrm{k}=\mathrm{K} /(\mathrm{N}+\mathrm{L}), \mathrm{u}(\mathrm{c})$ is the utility derived from per capita consumption, and finally the $\mathrm{F}(\mathrm{K}, \mathrm{L})$ production function.

We now have two separate accounting prices for the two population groups. In contrast to the original result presented by Arrow et al. (2003), the real wage $\left(F_{L}\right)$ appears in the shadow prices, since the older generation does not join production. We are thus interested in whether the RHS of (8) exceeds the increase in $\mathrm{k}$. When $g_{N}-g_{L}>0$, the RHS of (10) is positive, but the RHS of (9) may or may not be. When $g_{N}-g_{L}<0$, the opposite occurs. For comparison purposes, Hayashi and Saito (2011) project that the prefectural population in Miyagi will drop 19.7\% (or 0.63\% annually) from 2,360k in 2005 to $1,894 \mathrm{k}$ in 2040 . In our notation, $\frac{L}{N+L}=0.80, \frac{N}{N+L}=0.20, g_{N}=0.92 \%$, and $g_{L}=$ $-1.18 \%$ per annum. Given these parameters, the last term on the RHS of (8) is always negative, while the second term could also be negative if $\frac{u}{u^{\prime}}$ in (9) is too small. In sum,

17 We also have to bear in mind that population in reality is not independent of socioeconomic variables. Thus, there exists the paradox that even though a decreasing population requires less investment, more investment is needed to attract people to migrate into the region. We have to ignore this important point in this paper.

18 For the details of this result, see Yamaguchi (2014). 
the demographic pressure on the RHS of (8) to be smaller than the increase in capital per capita becomes even stronger in an ageing society. This explains why we cannot be optimistic about the future prospects of the population adjustment row in Table 10.

Several policy implications can be derived for demographics. First, investment in newer institutions should be accelerated, such as those that offer childcare or those that accept immigrants to be a valid element of the regional productive base. The nature of investment in produced capital should also change gradually to be directed towards platforms for commercial or trading activities, as well as the provision of nursery homes for newborns and elderly. The place of investment also matters: physical structures should not be located far from each other. It is also recommended that the local government save enough for future demographic change. Raising the participation rate of people over 65 would change the definition of $\mathrm{N}$ and thus improve comprehensive wealth per capita.

\section{Concluding remarks}

In this paper, we proposed a regional wealth index that can be used as a benchmark for investment into post-disaster reconstruction. Along with rationales for regional disaggregation of the wealth criterion, our results make an example of the fact that the national figures and regional ones indeed differ. Based on detailed local data and by assessing variables such as land, forest, fishery, excess burden of debts, and oil capital loss, we showed that comprehensive wealth as an indicator of sustainability has been gradually declining over the past decade, with this decrease especially marked after the 2011 disaster in the study area. Overall, we found that development in this region is assessed as barely sustainable in per capita terms. However, in forthcoming decades the population decrease in Miyagi Prefecture may negatively affect sustainability because of the ageing population.

Admittedly, this study suffers from some limitations, mostly due to data availability. For certain parameters and data (e.g., educational attainment), we used national aggregated data; capitalized ecosystem services are unaddressed. In assessing comprehensive wealth as a benchmark for post-disaster reconstruction, some aspects of human capital, including physical and health and detailed demographics are also crucial. Examples include the reports of post-traumatic stress disorder and the possible health concerns of the nuclear power plant accident in the neighboring Fukushima Prefecture. We wish to return to these issues in future research. 
References

Aronsson, T., Cialani, C., \& Löfgren, K.-G. (2012). Genuine saving and the social cost of taxation. Journal of Public Economics, 96, 211-7.

Aronsson, T. \& Löfgren, K.-G. (eds.) (2010). Handbook of environmental accounting. Cheltenham: Edward Elgar.

Arrow, K.J., Dasgupta, P., \& Mäler, K.-G. (2003). The genuine savings criterion and the value of population. Economic Theory, 21, 217-225.

Arrow, K., Dasgupta, P., Goulder, L., Daily, G., Ehrlich, P., Heal, G., Levin, S., Mäler, K.G., Schneider, S., Starrett, D., \& Walker, B. (2004). Are we consuming too much? Journal of Economic Perspectives, 18, 147-172.

Arrow, K.J., Dasgupta, P., Goulder, L., Mumford, K., \& Oleson, K. (2012). Sustainability and the measurement of wealth. Environment and Development Economics, 17, 317353.

Asheim, G.B. (1986). Capital gains and net national product in open economies. Journal of Public Economics, 59, 419-434.

Barbier, E. B. (2009). Ecosystems as natural assets. Now Publishers Inc.

Barro, R. \& Lee, J. (2011). Barro-Lee Educational Attainment Dataset, available online at: www.barrolee.com (accessed January 5, 2013)

Bolt, K., Matete, M., \& Clemens, M. (2002). Manual for Calculating Adjusted Net Savings, Environment Department, World Bank.

Boyd, J. \& Banzhaf, S. (2007). What are ecosystem services? The need for standardized environmental accounting units. Ecological Economics, 63, 616-626.

BP (2012), Statistical review of world energy.

Cohen-Cole, E., \& Fletcher, J. M. (2008). Is obesity contagious? Social networks vs. environmental factors in the obesity epidemic. Journal of Health Economics, 27(5), 1382-1387.

Daily, G. C., Polasky, S., Goldstein, J., Kareiva, P. M., Mooney, H. A., Pejchar, L., Ricketts, T., Salzman, J., \& Shallenberger, R. (2009). Ecosystem services in decision making: time to deliver. Frontiers in Ecology and the Environment, 7(1), 21-28.

Dasgupta, P. (2009). The welfare economic theory of green national accounts. Environmental and Resource Economics, 42, 3-38.

Dasgupta, P.S. \& Heal, G.M. (1979). Economic theory and exhaustible resources. New York: Cambridge University Press.

Dasgupta, P. \& Mäler, K.-G. (2000). Net national product, wealth, and social well-being. Environment and Development Economics, 5, 69-93. 
Development Bank of Japan (2011). Higashi nihon daishinsai shihon stock higai kingaku suikei (in Japanese).

Dixit, A., Hammond, P., \& Hoel, M. (1980). On Hartwick's rule for regular maximin paths of capital accumulation and resource depletion. Review of Economic Studies 47, 551556.

Dovern, J., Quaas, M. F., \& Rickels, W. (2014). A comprehensive wealth index for cities in Germany. Ecological Indicators, 41, 79-86.

Ferreira, S. and Hamilton, K. (2010). Comprehensive wealth, intangible capital, and development. World Bank Policy Research Working Paper No. 5452, Washington, DC: World Bank.

Fukushima Prefecture (2013), Annual report 2013, https://www.pref.fukushima.lg.jp/sec/37380a/ (accessed May 8, 2015) (in Japanese).

Hamilton, K. (2012). Comments on Arrow et al., 'Sustainability and the measurement of wealth'. Environment and Development Economics, 17, 356-361.

Hamilton, K. \& Atkinson, G. (2006). Wealth, welfare and sustainability, Cheltenham: Edward Elgar.

Hamilton, K. \& Bolt, K. (2004). Resource price trends and development prospects. Portuguese Economic Journal, 3, 85-97.

Hamilton, K. \& Clemens, M. (1999). Genuine savings rates in developing countries. World Bank Economic Review, 13, 333-356.

Harada, Y. (2012). Shinsai fukko giman no kouzu (in Japanese), Tokyo: Shincho-sha.

Hartwick, J.M. (1977). Intergenerational equity and the investing of rents from exhaustible resources. American Economic Review, 67, 972-974.

Hayashi, N. \& Saito, S. (2011). Iwate-ken, Miyagi-ken, Fukushima-ken no shourai suikei jinko (in Japanese). SERC Discussion Paper 11023, Tokyo: CRIEPI.

Hoshi, T. \& Ito, T. (2012). Defying gravity: how long will Japanese government bond prices remain high? NBER Working Paper 18287.

Kainou,K. (2013). Energy Consumption Statistics by Prefecture, available online at: http://www.rieti.go.jp/users/kainou-kazunari/energy/index.html (accessed January 5, 2014)

Mincer, J. (1974). Schooling, experience and earnings, New York: Columbia University Press.

Ministry of Internal Affairs and Communications (2008). Studies on information technology and regional productivity (in Japanese). Tokyo: MIAC.

Mitsuhashi, H. (2010). Chiiki innovation no dairi shihyo to shiteno TFP ni kansuru 
kenkyu (in Japanese). Discussion Paper No.65, Tokyo: MEXT.

Murota, Y. (2008). Estimates of 47 prefectural CO2 emissions (in Japanese), available online at: http://www.env.go.jp/earth/ondanka/sakutei_manual/kaitei_comm/com02/ext01.pdf (accessed January 1, 2013)

Nordhaus, W. \& Boyer, J. (2000). Warming the world, Cambridge, Massachusetts: The MIT Press.

Ollivier, T. \& Giraud, P.-N. (2010). Assessing sustainability, a comprehensive wealth accounting prospect: An application to Mozambique', Ecological Economics, 70, 503-512. Pearce, D. \& Atkinson, G. (1993). Capital theory and the measurement of sustainable development: an indicator of "weak" sustainability. Ecological Economics, 8, 103-108.

Romano, O., \& Ercolano, S. (2013). Who makes the most? Measuring the "urban environmental virtuosity”. Social Indicators Research, 112(3), 709-724.

Sefton, J. \& Weale, M. (1996). The net national product and exhaustible resource. Journal of Public Economics, 61, 21-47.

Sen, A. (1982). Choice, welfare and measurement. Cambridge, MA: Harvard University Press.

Tallis, H., Wolny, S., Lozano, J. S., Benitez, S., Saenz, S., \& Ramos, A. (2012). "Servicesheds" enable mitigation of development impacts on ecosystem services. Mimeo.

Tol, R.S.J. (2009). The economic effects of climate change. Journal of Economic Perspectives, 23, 29-51.

UNU-IHDP \& UNEP (2012). Inclusive wealth report 2012. New York: Cambridge University Press.

van der Ploeg, F. (2010). Rapacious resource depletion, excessive investment and insecure property rights: a puzzle. Environmental and Resource Economics, 48, 105128.

Vincent, J.R., Panayotou, T., \& Hartwick, J.M. (1997). Resource depletion and sustainability in small open economies. Journal of Environmental Economics and Management, 33, 274-286.

World Bank (2006). Where is the wealth of nations? Washington, DC: World Bank.

World Bank (2010). World development indicators 2010. Washington, DC: World Bank.

World Bank (2011). The changing wealth of nations: measuring sustainable development in the new millennium. Washington, DC: World Bank.

Yamaguchi, R. (2014). Inclusive wealth with a changing but aging population, Economics Letters, 124: 21-25. 
Figure 1. Map of Tohoku region

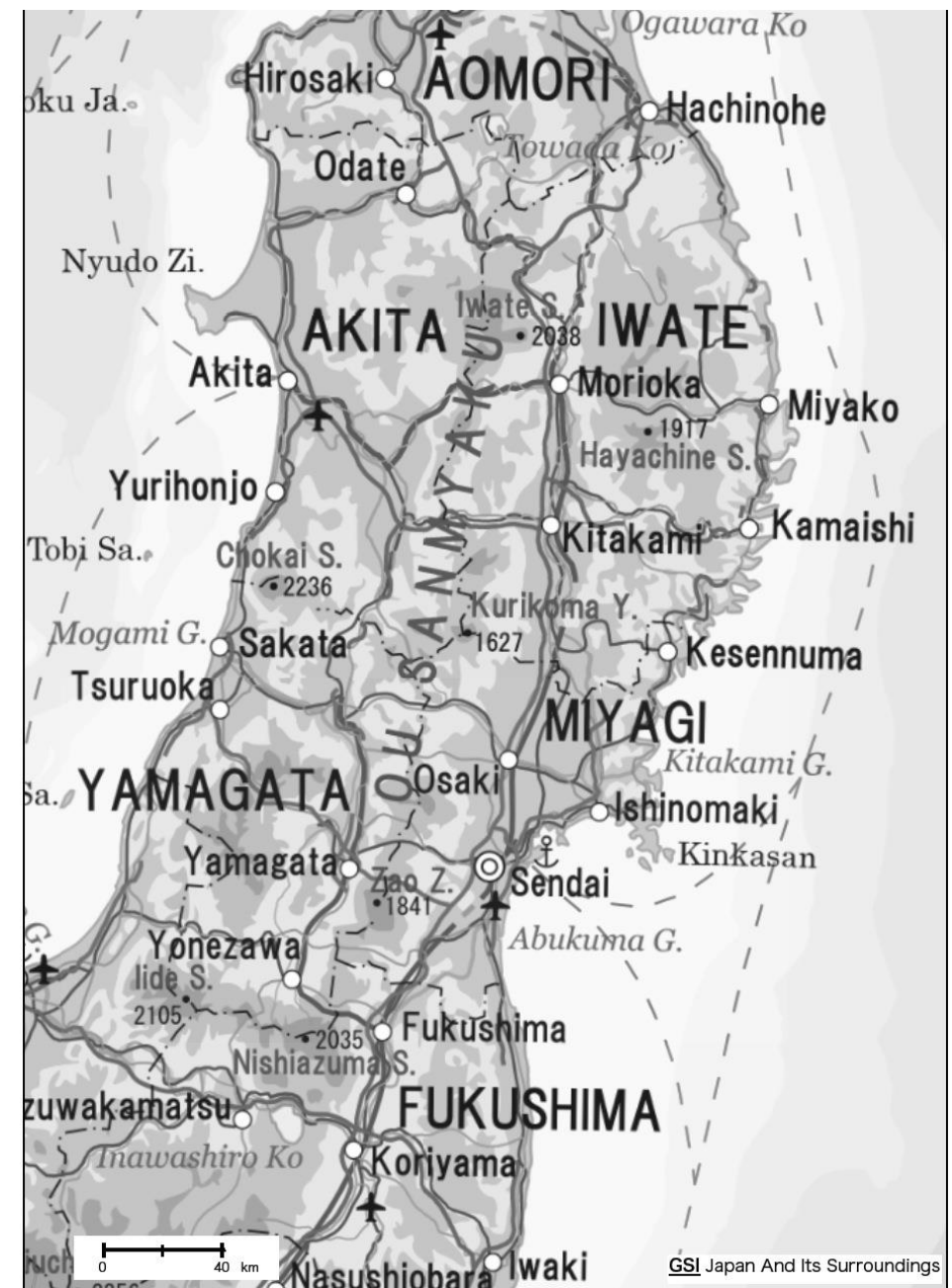

Source: Geospatial Information Authority of Japan

Note: Roughly, the east coast of the whole region shown above was devastated by either earthquake or its associated tsunami, of which Miyagi Prefecture is our study region. 
Table 1 Manufactured capital in Miyagi Prefecture in 2000, 2005, 2010, and 2011

\begin{tabular}{lcccc}
\hline & 2000 & 2005 & 2010 & 2011 \\
\hline Value of capital stock (\$ millions) & 282,778 & 287,793 & 278,270 & 262,701
\end{tabular}

Source: Authors' calculation based on Miyagi Prefecture data.

Table 2 Human capital in Miyagi Prefecture in 2000, 2005, 2010, and 2011

\begin{tabular}{lrrrr}
\hline & \multicolumn{1}{c}{2000} & \multicolumn{1}{c}{2005} & \multicolumn{1}{c}{2010} & \multicolumn{1}{c}{2011} \\
\hline Adult population (thousands) & 2,010 & 2,043 & 2,038 & 2,030 \\
Human capital stock (thousands) & 5,086 & 5,321 & 5,454 & 5,433 \\
Value of human capital (\$ millions) & 914,532 & 956,639 & 980,695 & 976,845 \\
\hline
\end{tabular}

Source: Labor Force Survey and authors' calculation.

Table 3 Fishery resource stock in Miyagi Prefecture in 2005, 2010, and 2011

\begin{tabular}{lrrr}
\hline & \multicolumn{1}{c}{2005} & \multicolumn{1}{c}{2010} & \multicolumn{1}{c}{2011} \\
\hline Fish stock (thousands of tons) & 584 & 341 & 644 \\
Value of fish stock (\$ millions) & 6,562 & 4,271 & 8,848
\end{tabular}

Source: Authors' calculation.

Table 4 Forest stock in Miyagi Prefecture in 2000, 2005, 2010, and 2011

\begin{tabular}{lrrrr}
\hline & \multicolumn{1}{c}{2000} & \multicolumn{1}{c}{2005} & \multicolumn{1}{c}{2010} & \multicolumn{1}{c}{2011} \\
\hline Total forest area (ha) & 277,061 & 276,714 & 280,009 & \multicolumn{1}{c}{279,444} \\
Total forest volume (1,000 m $\left.{ }^{3}\right)$ & 45,340 & 50,400 & 55,486 & 56,420 \\
Value of forest stock (\$ millions) & 70,431 & 57,946 & 63,784 & 64,856 \\
\hline
\end{tabular}

Source: Calculated from Prefectural Forest Resources and assumptions in Bolt et al. (2002), FAO (2010), and Lampietti and Dixon (1995).

Table 5 Agricultural land stock in Miyagi Prefecture in 2000, 2005, 2010, and 2011

\begin{tabular}{lrrrr}
\hline & \multicolumn{1}{c}{2000} & \multicolumn{1}{c}{2005} & \multicolumn{1}{c}{2010} & \multicolumn{1}{c}{2011} \\
\hline Paddy fields (ha) & 114,820 & 111,820 & 110,250 & 101,930 \\
Other fields (ha) & 26,910 & 26,172 & 26,036 & 24,258 \\
Value of total fields (\$ millions) & 29,069 & 28,289 & 28,028 & 26,023 \\
\hline
\end{tabular}

Source: Calculated from MAFF statistics.

Table 6 Carbon emissions, shadow values, and impact on Miyagi Prefecture in 2000, 
2005, 2010, and 2011

\begin{tabular}{|c|c|c|c|c|}
\hline & 2000 & 2005 & 2010 & 2011 \\
\hline Emissions (thousands of tC) & 4,184 & 4,549 & 4,090 & 4,294 \\
\hline Social cost of emissions ( $\$$ millions) & 209 & 227 & 205 & 215 \\
\hline $\begin{array}{l}\text { Impact of } 2.5 \text { degree warming } \\
\text { ( } \$ \text { millions) }\end{array}$ & 410 & 397 & 373 & 356 \\
\hline
\end{tabular}

Source: Emissions are taken from Kainou (2013), from which the social cost of emissions is calculated using $\$ 50 / \mathrm{tC}$. For the sake of comparison, the impact of 2.5 degree warming is calculated as $0.5 \%$ of regional GDP on the fourth row.

Table 7 Oil consumption, oil prices, and capital loss in 2000, 2005, 2010, and 2011

\begin{tabular}{|c|c|c|c|c|}
\hline & 2000 & 2005 & 2010 & 2011 \\
\hline $\begin{array}{l}\text { Oil and gas consumption (thousands } \\
\text { toe) }\end{array}$ & 5,261 & 5,399 & 5,132 & 5,844 \\
\hline World oil and gas consumption ( $\mathrm{m}$ toe) & 5,746 & 6,399 & 6,875 & 6,965 \\
\hline World oil and gas reserves ( $b$ toe) & 310 & 340 & 398 & 413 \\
\hline Region's capital loss ( $\$$ millions) & - & 16,431 & 20,830 & 5,679 \\
\hline
\end{tabular}

Source: Oil and gas consumption is calculated as the summation of oil products, light oil, heavy fuel oil, oil gas, natural gas, "town gas," and oil and gas fired to generate electricity. The latter is estimated from the proportion of Miyagi Prefecture in the final consumption of electricity data from Tohoku Electric Power Company. The capital loss for 2005, 2010, and 2011 represents the total loss incurred in the periods 2001-2005, 2006-2010, and 2011, respectively.

Table 8 Marginal excess burden of general deficits in 2000, 2005, 2010, and 2011

\begin{tabular}{lcccc}
\hline & 2000 & 2005 & 2010 & 2011 \\
\hline Marginal excess burden (\$ millions) & 1,977 & 1,147 & 2,084 & 2,122 \\
\hline Source: Calculated from the International Monetary & Fund, World Economic Outlook \\
Database. The general government deficits are divided according to the regional GDP \\
ratio. The marginal excess burden is assumed to be 0.3 multiplied by the deficits.
\end{tabular}


Figure 2 The breakdown of comprehensive wealth in 2010 (left) and 2011 (right)
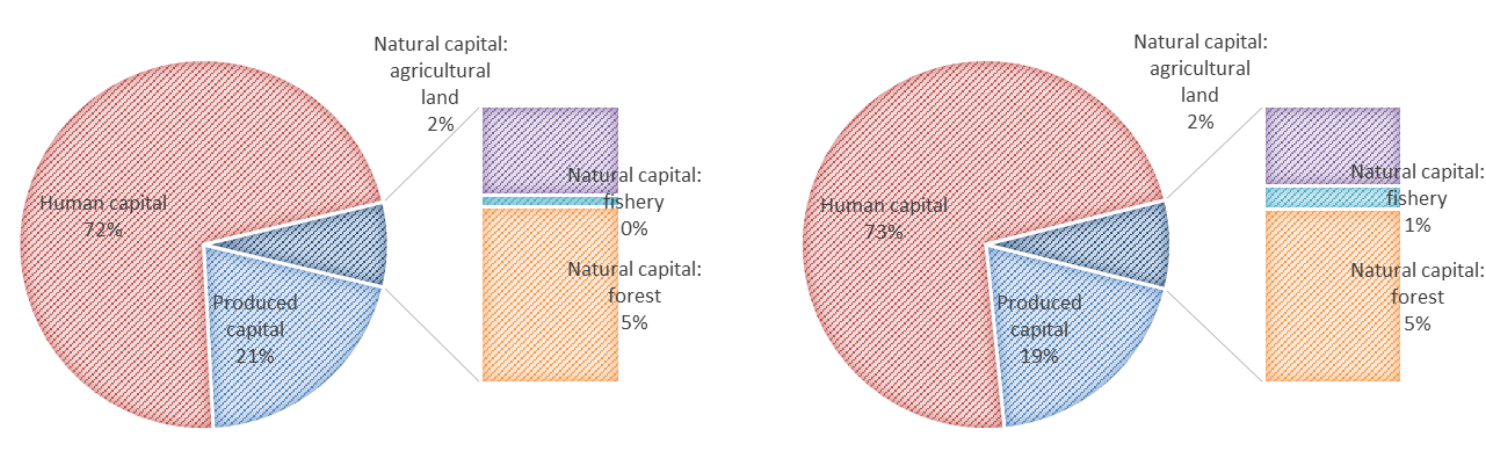

Table 9 Average comprehensive wealth change per annum (millions of dollars)

\begin{tabular}{llrrr}
\hline & & 2000-2005 & 2005-2010 & 2010-2011 \\
\hline Produced capital & & 1,003 & $-1,905$ & $-15,569$ \\
Human capital & & 8,422 & 4,811 & $-3,850$ \\
Natural capital: & Agricultural land & -156 & -52 & $-2,005$ \\
& Fishery & N.A. & -458 & 4,577 \\
& Forest & $-2,497$ & 1,168 & 1,072 \\
& Carbon damage & -208 & -216 & -215 \\
Oil capital gains & & $-3,286$ & $-4,166$ & $-5,679$ \\
Marginal excess burden & $-1,551$ & $-1,339$ & $-2,122$ \\
Comprehensive wealth & 3,038 & $-2,157$ & $-23,790$ \\
\hline
\end{tabular}

Table 10 Comprehensive wealth growth rate per annum (percent)

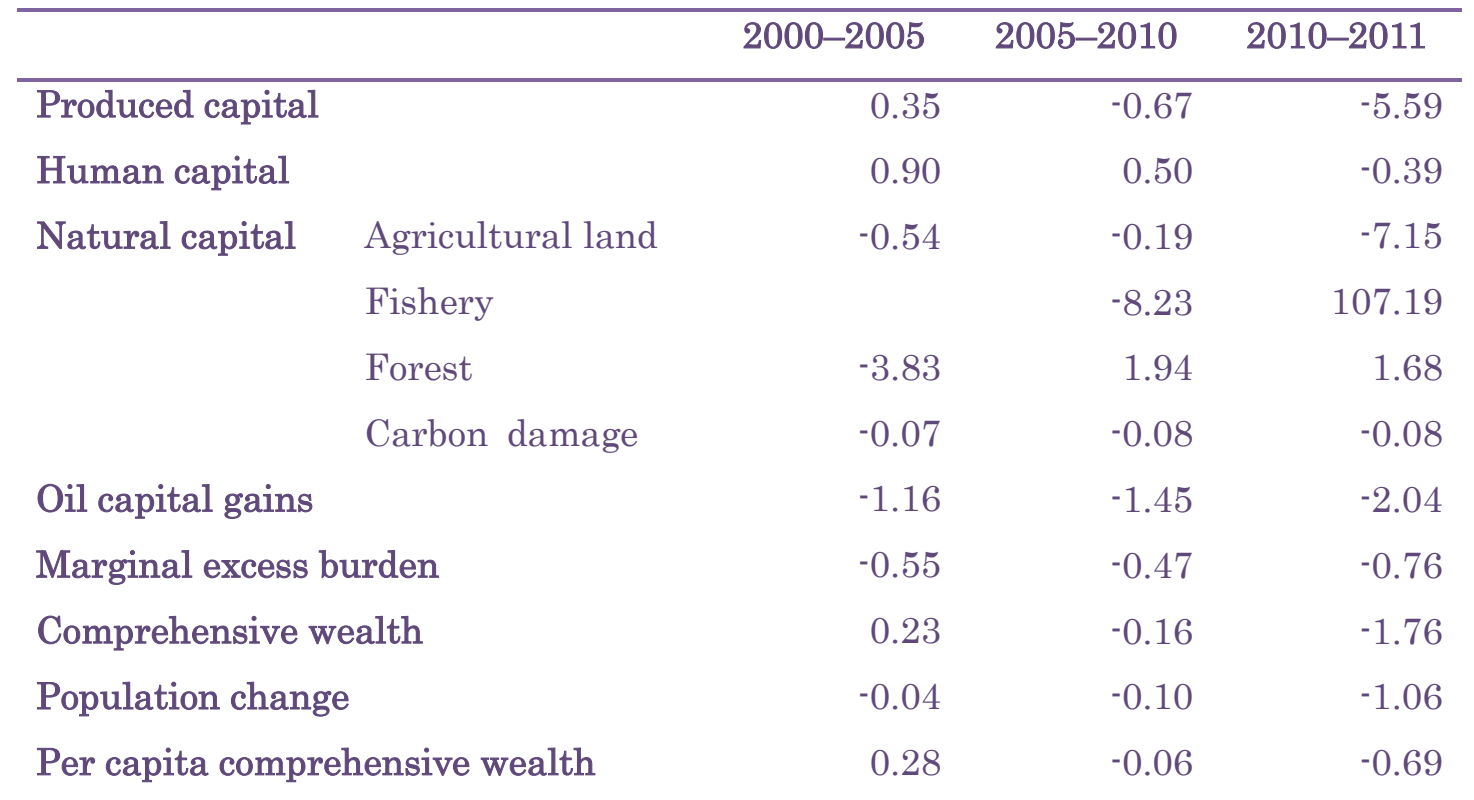

Note: The change in produced capital in 2010-2011 only reflects earthquake 
damage and ignores depreciation. The change rates for carbon damage, oil capital gains, and the marginal excess burden are the changes compared with the produced capital in the previous period.

Figure 3: Average annual change of components of comprehensive wealth (upper panel) and the equivalent figure from UNU-IHDP and UNEP (2014), adjusted for the population size of the study region (lower panel) (million dollars)

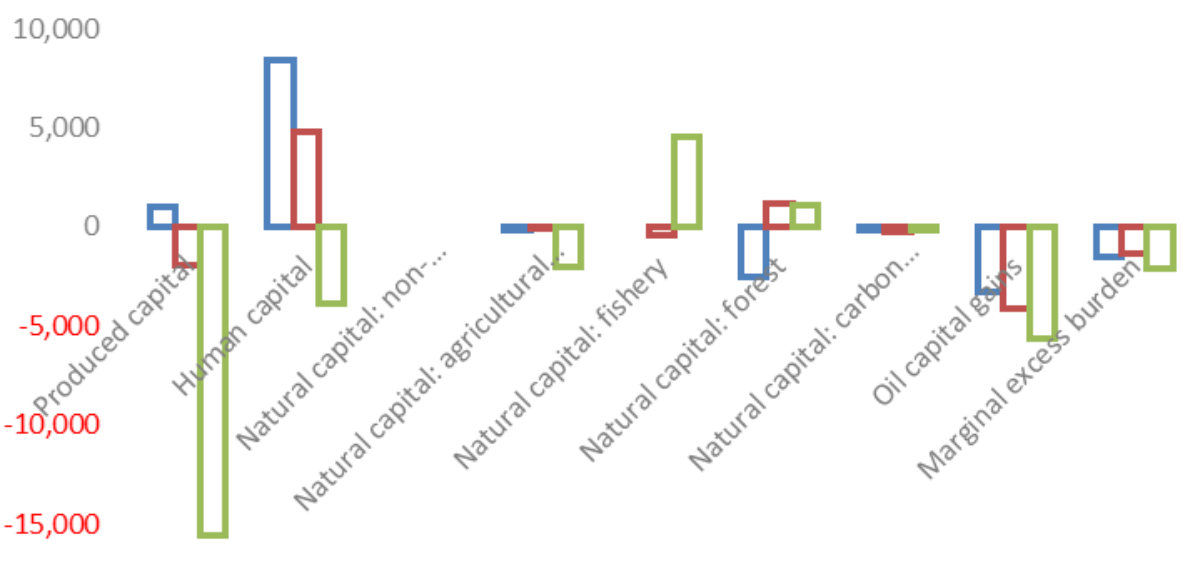

$-20,000$

10,000

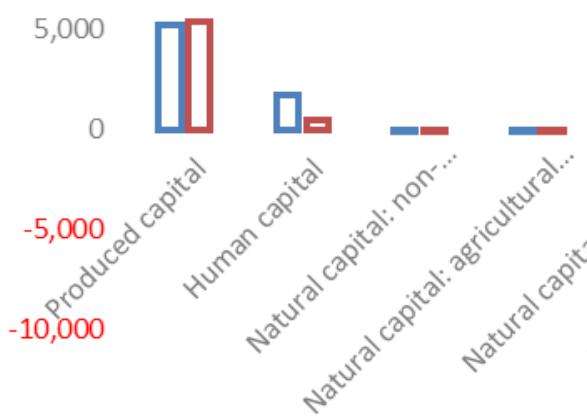

$-15,000$

$-20,000$ 
Table 11 Sensitivity analysis of comprehensive wealth growth rate per annum

(A) Discount rate

\begin{tabular}{lrrr}
\hline & $2000-2005$ & $2005-2010$ & $2010-2011$ \\
\hline Lower discounting (2\%) & $0.12 \%$ & $0.15 \%$ & $-0.43 \%$ \\
Base case (5\%) & $0.28 \%$ & $-0.06 \%$ & $-0.69 \%$ \\
Higher discounting (8\%) & $0.27 \%$ & $-0.21 \%$ & $-0.94 \%$
\end{tabular}

(B) Remaining working years of human capital

\begin{tabular}{lrrr}
\hline & $2000-2005$ & $2005-2010$ & $2010-2011$ \\
\hline Lower case (10 years) & $0.03 \%$ & $-0.31 \%$ & $-1.21 \%$ \\
Base case (20 years) & $0.28 \%$ & $-0.06 \%$ & $-0.69 \%$ \\
Higher case (30 years) & $0.37 \%$ & $0.04 \%$ & $-0.50 \%$ \\
\hline
\end{tabular}

(C) Catchability coefficient

\begin{tabular}{lrrr}
\hline & $2000-2005$ & $2005-2010$ & $2010-2011$ \\
\hline Lower catchability (0.0005) & $0.38 \%$ & $-0.09 \%$ & $-0.35 \%$ \\
Base case (0.001) & $0.28 \%$ & $-0.06 \%$ & $-0.69 \%$ \\
Higher catchability (0.01) & $0.19 \%$ & $-0.03 \%$ & $-1.00 \%$ \\
\hline
\end{tabular}

(D) Social cost of carbon

\begin{tabular}{lrrr}
\hline & $2000-2005$ & $2005-2010$ & $2010-2011$ \\
\hline Lower cost $(\$ 15)$ & $0.29 \%$ & $-0.05 \%$ & $-0.68 \%$ \\
Base case $(\$ 50)$ & $0.28 \%$ & $-0.06 \%$ & $-0.69 \%$ \\
Higher cost $(\$ 500)$ & $0.13 \%$ & $-0.21 \%$ & $-0.84 \%$ \\
\hline
\end{tabular}

(E) Oil price change

\begin{tabular}{lrrr}
\hline & $2000-2005$ & $2005-2010$ & $2010-2011$ \\
\hline Lower growth (-5\%) & $0.59 \%$ & $0.26 \%$ & $-0.26 \%$ \\
Base case (5\%) & $0.28 \%$ & $-0.06 \%$ & $-0.69 \%$ \\
Higher growth (20\%) & $-1.00 \%$ & $-3.40 \%$ & $-6.79 \%$ \\
\hline
\end{tabular}

(F) Marginal excess burden

\begin{tabular}{lrrr}
\hline & $2000-2005$ & $2005-2010$ & $2010-2011$ \\
\hline Lower burden (0.1) & $0.21 \%$ & $-0.14 \%$ & $-0.73 \%$ \\
Base case (0.3) & $0.28 \%$ & $-0.06 \%$ & $-0.69 \%$ \\
Higher burden (0.5) & $0.05 \%$ & $-0.27 \%$ & $-0.94 \%$ \\
\hline
\end{tabular}


Appendix: Assumptions and sources of calculation

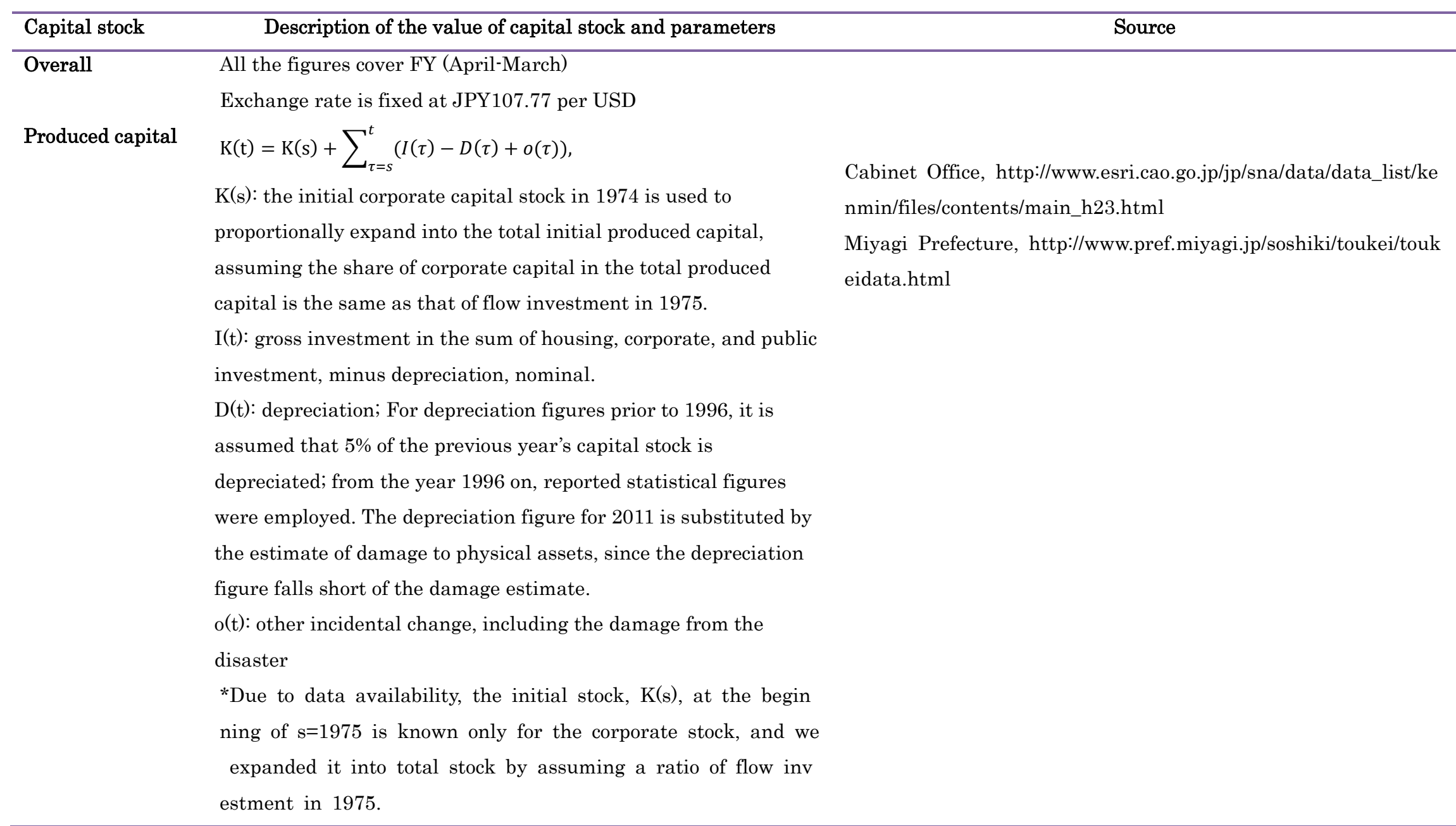




\begin{tabular}{|c|c|c|}
\hline \multirow[t]{11}{*}{ Human capital } & $p_{H}(\mathrm{t}) \mathrm{H}(\mathrm{t})=p_{H}(\mathrm{t}) \mathrm{P}(\mathrm{t}) \mathrm{e}^{\mathrm{rT}}$, where & \\
\hline & \multirow[t]{2}{*}{$\mathrm{P}(\mathrm{t})$ : the population of persons aged 15 years old and older at $\mathrm{t}$} & Labor Force Survey, \\
\hline & & http://www.pref.miyagi.jp/soshiki/toukei/toukeidata.html \\
\hline & $\mathrm{r}$ : the rate of return on education $(8.5 \%)$ & Arrow et al. (2012) \\
\hline & T: educational attainment & Barro and Lee (2011) \\
\hline & $p_{H}(\mathrm{t})=\int_{t}^{t+m} \frac{W(\tau)}{\mathrm{L}(\tau) \mathrm{e}^{\mathrm{rT}}} \mathrm{e}^{-\delta \tau} d \tau$ where & \\
\hline & $\mathrm{W}(\mathrm{t})$ : total wage bill & prefectural employee wages, Miyagi Prefecture, \\
\hline & & http://www.pref.miyagi.jp/soshiki/toukei/toukeidata.html \\
\hline & $\mathrm{L}(\mathrm{t})$ : the employed proportion of the adult population & Labor Force Survey, \\
\hline & $\delta:$ the social discount rate (5\% per annum) & http://www.stat.go.jp/data/roudou/pref/index.htm \\
\hline & $\mathrm{m}$ : the average remaining working years (20 years) & \\
\hline Natural & $p_{S}(\mathrm{t}) \mathrm{S}(\mathrm{t})=p_{S} \mathrm{H} / \mathrm{qE}$, where & \\
\hline \multirow[t]{7}{*}{ Fishery } & S: fish stock (for tuna, bonito, and other long line fishery) & own calculation, from $\mathrm{S}=\mathrm{H} / \mathrm{qE}$ \\
\hline & H: fish harvest & Ministry of Agriculture, Forestry and Fisheries (MAFF), \\
\hline & q: coefficient of catchability (assumed to be $0.1 \%$ ) & http://www.maff.go.jp/j/tokei/kouhyou/kaimen_gyosei \\
\hline & E: number of fishing vessels over 1 ton (for tuna, bonito, and & Vessels Statistics, Fisheries Agency, available upon request from \\
\hline & other long line fishery) & Miyagi Prefecture \\
\hline & $p_{S}(\mathrm{t}):$ market price of frozen tuna, weighted average & Fisheries Agency, \\
\hline & & http://www.jfa.maff.go.jp/j/tuna/kakaku/index.html \\
\hline \multirow{6}{*}{$\begin{array}{l}\text { Natural } \\
\text { Forest }\end{array}$} & Timber value: the rental rate ( $50 \%)$ of the unit value of industrial & Forest area and volume: Prefectural Forest Resources, available \\
\hline & roundwood removals, multiplied by the volume of conifers and & upon request from Miyagi Prefecture \\
\hline & broadleaves & Rental rate: Bolt et al. (2002) \\
\hline & The value of non-timber forest benefits (NTFB): $\$ 190$ per hectare & Unit value of industrial roundwood removals: FAO (2010). They \\
\hline & of total forest area, which is inclusive of the accessibility & are available only for the years 1990,2000 , and 2005 , and the \\
\hline & assumption & values for the other years are linearly interpolated. \\
\hline
\end{tabular}


calculated assuming the discount rate of $5 \%$ and infinite horizon.

Natural capital: The shadow price of agricultural land stock per hectare is the

agricultural land present value of the agricultural rent the unit land yields from

(cropland and now to the infinite future. The annual rent per hectare is

pastureland)

calculated by dividing total output by arable land, assuming the rental rate of $80 \%$, separately for rice and others. We use the average annual output between 2000 and 2012.

Natural capital: The social cost of prefectural carbon emission is deducted from carbon damage produced capital stock.

The social cost of emissions is calculated using $\$ 50 / \mathrm{tC}$.

For the sake of comparison, the impact of 2.5 degree warming is calculated as $0.5 \%$ of regional GDP.

Oil capital gains Prefectural consumption portion of the global capital gains on oil and gas is deducted from produced capital stock. For prefectural consumption of oil and gas, the following items are included to calculate the share in global: oil products, light oil, heavy fuel oil, oil gas, natural gas, town gas, fuel oil for electricity, crude oil for electricity, natural gas for electricity, and LNG for electricity.

Marginal excess Marginal excess burden (MEB) of net increase in national public burden debts are deducted from produced capital. To do so, prefectural
Annual agricultural output in the prefecture: Ministry of Agriculture, Forestry and Fisheries (MAFF),

http://www.maff.go.jp/j/tokei/kouhyou/nougyou sansyutu/tyouki/i ndex.html

Output in the devastated region (not directly used): MAFF,

http://www.maff.go.jp/j/tokei/saigai/pdf/hisai_sanshutsu_12s.pdf Amount of physical agricultural land: MAFF,

http://www.maff.go.jp/j/tokei/kouhyou/sakumotu/menseki/

Discount rate: $5 \%$ per year

Prefectural carbon emission: Kainou (2013)

Shadow value of carbon emission: Tol (2009)

Impact/GDP ratio: Nordhaus and Boyer (2000)

Global oil and gas proven reserve: BP (2012)

Price change (5\%): Arrow et al. (2012)

Global consumption of oil and gas: BP (2012)

Prefectural consumption of oil and gas: Kainou (2013)

The breakdown of fuel consumption for electricity is allocated using the proportion of Miyagi Prefecture in the final consumption of electricity data from Tohoku Electric Power Company Annual Report.

General government net lending/borrowing: Cabinet Office of Japan, International Monetary Fund, World Economic Outlook 
http://www.imf.org/external/pubs/ft/weo/2013/01/weodata/index.a spx

MEB/debt ratio (0.3): Aronsson et al. (2012), middle case

Population change Population change rate is added to the change rate of wealth per Miyagi Prefecture,

capita

http://www.pref.miyagi.jp/soshiki/toukei/suikei-nen.html 